\title{
Mechanical behavior of bulk direct composite versus block composite and lithium disilicate indirect Class II restorations by CAD-FEM modeling.
}

DOI:

10.1016/j.dental.2017.03.014

\section{Document Version}

Accepted author manuscript

Link to publication record in Manchester Research Explorer

Citation for published version (APA):

Ausiello, P., Ciaramella, S., Fabianelli, A., Gloria, A., Martorelli, M., Lanzotti, A., \& WATTS, D. C. (2017). Mechanical behavior of bulk direct composite versus block composite and lithium disilicate indirect Class II restorations by CAD-FEM modeling. Stress Distributions in Class II restorations. Dental Materials, 33. https://doi.org/10.1016/j.dental.2017.03.014

\section{Published in:}

Dental Materials

\section{Citing this paper}

Please note that where the full-text provided on Manchester Research Explorer is the Author Accepted Manuscript or Proof version this may differ from the final Published version. If citing, it is advised that you check and use the publisher's definitive version.

\section{General rights}

Copyright and moral rights for the publications made accessible in the Research Explorer are retained by the authors and/or other copyright owners and it is a condition of accessing publications that users recognise and abide by the legal requirements associated with these rights.

\section{Takedown policy}

If you believe that this document breaches copyright please refer to the University of Manchester's Takedown Procedures [http://man.ac.uk/04Y6Bo] or contact uml.scholarlycommunications@manchester.ac.uk providing relevant details, so we can investigate your claim.

\section{OPEN ACCESS}




\section{Mechanical behavior of bulk direct composite versus block composite and lithium disilicate indirect Class II restorations by CAD-FEM modeling.}

Pietro AUSIELLO ${ }^{1 *}$, Stefano CIARAMELLA ${ }^{2}$, Andrea FABIANELLI ${ }^{3}$, Antonio GLORIA $^{4}$, Massimo MARTORELLI ${ }^{2}$, Antonio LANZOTTI ${ }^{2}$, David C WATTS ${ }^{5}$

1 School of Dentistry - University of Naples Federico II, Italy.

2 Department of Industrial Engineering, Fraunhofer JL IDEAS - University of Naples Federico II, Italy;

3 University of Brescia, Italy.

4 Institute of Polymers, Composites and Biomaterials - National Research Council of Italy, Napoli, Italy;

5 School of Medical Sciences and Photon Science Institute, University of Manchester, United Kingdom

* Corresponding author: pietro.ausiello@unina.it

Short Title:

Stress Distributions in Class II restorations

Accepted for Publication: Dental Materials (2017) vol 33 


\begin{abstract}
Objectives: To study the influence of resin based and lithium disilicate materials on the stress and strain distributions in adhesive class II mesio-occlusal-distal (MOD) restorations using numerical finite element analysis (FEA). To investigate the materials combinations in the restored teeth during mastication and their ability to relieve stresses.
\end{abstract}

Methods: One 3D model of a sound lower molar and three 3D class II MOD cavity models with $95^{\circ}$ cavity-margin-angle shapes were modelled. Different material combinations were simulated: model A, with a $10 \mu \mathrm{m}$ thick resin bonding layer and a resin composite bulk filling material; model $\mathrm{B}$, with a 70 $\mu \mathrm{m}$ resin cement with an indirect CAD-CAM resin composite inlay; model C, with a $70 \mu \mathrm{m}$ thick resin cement with an indirect lithium disilicate machinable inlay. To simulate polymerization shrinkage effects in the adhesive layers and bulk fill composite, the thermal expansion approach was used. Shell elements were employed for representing the adhesive layers. 3D solid CTETRA elements with four grid points were employed for modelling the food bolus and tooth. Slide-type contact elements were used between the tooth surface and food. A vertical occlusal load of $600 \mathrm{~N}$ was applied, and nodal displacements on the bottom cutting surfaces were constrained in all directions. All the materials were assumed to be isotropic and elastic and a static linear analysis was performed.

Results: Displacements were different in Models A, B and C. Polymerization shrinkage hardly affected model A and mastication only partially affected mechanical behavior. Shrinkage stress peaks were mainly located marginally along the enamel-restoration interface at occlusal and mesiodistal sites. However, at the internal dentinal walls, stress distributions were critical with the highest maximum stresses concentrated in the proximal boxes. In models B and C, shrinkage stress was only produced by the $70 \mu \mathrm{m}$ thick resin layer, but the magnitudes depended on the Young's modulus (E) of the inlay materials. Model B mastication behavior (with E=20 GPa) was similar to the sound tooth stress relief pattern. Model B internally showed differences from the sound tooth model but reduced maximum stresses than model A and partially than model C. Model C (with E= $70 \mathrm{GPa}$ ) behaved similarly to model $\mathrm{B}$ with well redistributed stresses at the occlusal margins and the lateral sides with higher stress concentrations in the proximal boxes. Models B and C showed a more favorable performance than model A with elastic biomechanics similar to the sound tooth model.

Significance: Bulk filling resin composite with 1\% polymerization shrinkage negatively affected the mechanical behavior of class II MOD restored teeth. Class II MOD direct resin composite showed greater potential for damage because of higher internal and marginal stress evolution during resin polymerization shrinkage. With a large class II MOD cavity an indirect composite or a lithium disilicate inlay restoration may provide a mechanical response close to that of a sound tooth.

Keywords: CAD; Finite Element Analysis; Composite resins; Lithium Disilicate; MicroComputed Tomography; Stress analysis. 


\section{Introduction.}

Today materials employed in adhesive dentistry to restore decayed teeth are principally resin composite [1] and ceramic systems, such as lithium disilicate [2]. The former incorporate an organic matrix, formed from monomers such as Bis-GMA and TEGDMA and a reinforcing phase of inorganic glass particles that are micro or nano-structured. A silane coupling agent chemically links the two phases. They perform adequately in both anterior and posterior situations [3]. Lithium disilicate is a pressed glass ceramic material with good physical properties and clinical performance [4]. Resin composites are used in class I and in II MOD adhesive restorations but there is some evidence contraindicating their use via adhesive direct techniques in large size cavities [5]. This is mainly due to shrinkage stress effects on the adhesive interfaces [6-9].

Bulk-fill composite materials showed comparable results to traditional composited regarding their shrinkage properties [10]. Clinically, there may be a preference for indirect resin composite inlays created by milling industrially cured blocks in combination with adhesive luting materials [11]. Glass ceramic lithium disilicate restorations can also reduce polymerization shrinkage effects. In both cases this is restricted to the thin composite cement layer [7] rather than to the bulk filling material. Also bulk filling materials for direct use in Class I and Class II cavities are now established [12-15]. Nevertheless, fatigue through mechanical loading, can marginally damage composite restorations and lead to debonding and bacterial penetration along marginal gaps [16]. Functional modelling by 3Dfinite element analysis has suggested acceptable performance of Class II inlay adhesive composite restorations [17]. Furthermore, stress propagation and potential crack growth inside adhesively restored teeth under occlusal loading have been simulated. Results indicated that principal stress behavior of class II MOD restored teeth can be influenced by several factors such as class II cavitymargin-angle and different bolus stiffness [18]. However, the effect of restorative material selection requires investigation. This could clinically influence whether or not restoration behavior as close as possible to the sound tooth could be obtained.

The aim of the present study was to determine, by means of 3D-FEA under shrinking and loading conditions, the displacements and the stress distribution in a class II MOD cavity for the following three representative restoration scenarios, using: a) an adhesively bonded bulk fill direct resin composite material; b) a $70 \mu \mathrm{m}$ resin cement layer beneath a milled composite inlay and c) a $70 \mu \mathrm{m}$ resin cement layer beneath a lithium disilicate inlay machinable restoration. 


\section{Materials and methods.}

A 3D model of a human lower molar, used in previous investigations [17, 18], was considered in this study. The adopted procedure may be summarized as follows. First, the 3D CAD model of the sound tooth was built-up starting from micro-CT scan images [17]. Then, the restored tooth modeled properly [18]. Finally, numerical FEA simulations were performed to understand the influence of different resin based and lithium disilicate materials in terms of stress and strain distributions.

\section{Generation of tooth solid model.}

A 3D model of the sound tooth was digitized with a high resolution micro-CT scanner system (1072, SkyScan, Belgium). A total of 471 slices were collected using an image resolution $1024 \times 1024$ pixels, a voltage at $110 \mathrm{kV}$ and a voxel dimension of $19.47 \mu \mathrm{m}$. As the aim of this study concerned the macrostructure of the tooth, there was no need for all slices. Just 91 slices were sufficient. Iso-surfaces were detected by using the "K-Means" clustering algorithm implemented in [17] that operates by grouping image pixels, defined with their gray scale, into K groups/clusters. A constant pixel value (the centroid of the cluster) was associated with each cluster. By using this classification, for the ith slice, logical matrices (pixel mask) of pixels were introduced: the value of the th pixel was equal to " 1 " if it belongs to the kth cluster, otherwise it was assumed equal to " 0 ". In the present application, the cluster number was two: for enamel and dentin regions. Once clustering classification had been performed for all image slices, 3D tessellated surfaces were created using the marching-cube algorithm. This numerical procedure allows connection between pixels having the same value on different slices. The "isosurface" function available in Matlab ${ }^{\circledR}$ was used for the surface tessellation. Then $3 \mathrm{D}$ volumes were created by using SolidWorks ${ }^{\circledR}$ CAD software.

The solid model of the restored tooth was created starting from the sound one, with Evolve 2015@ (solidThinking Inc, Altair Company) software. The tooth model was placed in the coordinate system in such a way that the X-axis identified the buccolingual direction, the Y-axis the mesiodistal, and the Zaxis was oriented upwards (Fig. 1a). Using the trim tool, part of the two solids was removed by projecting the profile curves onto it. One solid model with margin angle of the cavity restoration $\alpha=$ $95^{\circ}$ (Fig. $1 \mathrm{~b}$ and $1 \mathrm{c}$ ) was created. The cavity design was characterized by a flat floor and sharp internal line angles. Solid food was also modelled on the occlusal surface. With regard to the crown, the buccolingual and mesiodistal diameters were $10.5 \mathrm{~mm}$ and $12.4 \mathrm{~mm}$, respectively, whereas the cervico-occlusal length was $7.8 \mathrm{~mm}$. The model was cut in the cervical area to obtain the final crown.

\section{Numerical simulation.}

The solid models of sound and restored tooth were imported into the HyperWork ${ }^{\circledR}$ 14.0 (Altair Engineering Inc) environment, using the IGES format.

To investigate the influence of different resin based and glass ceramic dental materials in terms of stress and strain distributions, three FE models of restored tooth with different restored materials were built-up and analyzed. Numerical results were also compared with sound tooth behavior. Each of the tissues in the tooth models was defined in term of the mechanical properties. For the food bolus, the values of Young's modulus and Poisson's ratio were assumed to be $10 \mathrm{MPa}$ and 0.3 , respectively. Values of $80 \mathrm{GPa}$ and 0.30 were assumed for enamel, $18 \mathrm{GPa}$ and 0.23 for dentin. Different values of 
Young's modulus and Poisson's ratio were used for the restoring materials. The data are listed in Table 1. Thus, four FE models were successively analyzed (Table 2). A 3D mesh was created. Each tooth model was divided into 3D solid CTETRA elements with four grid points. In the FE model generation, some technical enhancements were used to increase the structural relevance of the developed model.

\begin{tabular}{lccccc}
\hline \multicolumn{1}{c}{ Material } & $\begin{array}{c}\text { Young's } \\
\text { modulus } \\
(\mathbf{M P a})\end{array}$ & $\begin{array}{c}\text { Poisson's } \\
\text { ratio }\end{array}$ & $\begin{array}{c}\text { Thickness } \\
(\boldsymbol{\mu m})\end{array}$ & $\begin{array}{c}\text { Vol. Shrinkage } \\
(\%)\end{array}$ & $\begin{array}{c}\text { Linear thermal } \\
\text { expansion coefficient }\end{array}$ \\
\hline Dentin & 18000 & 0.23 & -- & -- & -- \\
Enamel & 80000 & 0.30 & -- & -- & -- \\
Food bolus & 10 & 0.30 & -- & -- & 0.090 \\
Resin cement & 6000 & 0.30 & 70 & 2.7 & 0.033 \\
Adhesive Bonding & 3000 & 0.30 & 10 & 1.0 & 0.033 \\
Bulk Fill composite & 12000 & 0.25 & -- & 1.0 & -- \\
Block composite & 20000 & 0.25 & -- & -- & -- \\
\hline Lithium Disilicate & 70000 & 0.25 & -- & -- & \\
\hline
\end{tabular}

Table 1 - Mechanical properties of materials: Young's modulus, Poisson's ratio and linear shrinkage

All the models were subjected to the load during the closing phase of the chewing cycle. The variability of chewing function, depending on the contact between tooth surface and food bolus, was considered. With regard to the occlusal surfaces, slide-type contact elements were used between tooth surface and food.

\begin{tabular}{|c|c|c|c|c|c|c|c|c|}
\hline Model & Type & $\begin{array}{c}\text { Restoration } \\
\text { method }\end{array}$ & $\begin{array}{l}\text { Restored } \\
\text { material }\end{array}$ & $\begin{array}{c}\text { Adhesive } \\
\text { layer }\end{array}$ & $\begin{array}{l}\text { Total \# of } \\
\text { Grids }\end{array}$ & $\begin{array}{l}\text { Total \# of } \\
\text { Elements }\end{array}$ & $\begin{array}{c}\text { Total \# of } \\
\text { Contact } \\
\text { Elements } \\
\end{array}$ & $\begin{array}{c}\text { Total \# of } \\
\text { Degrees of } \\
\text { Freedom }\end{array}$ \\
\hline $\mathbf{S}$ & sound & -- & -- & -- & 54281 & 217033 & 9733 & 185712 \\
\hline $\mathbf{A}$ & restored & direct & $\begin{array}{l}\text { Bulk Fill } \\
\text { composite }\end{array}$ & $\begin{array}{l}\text { Adhesive } \\
\text { bonding }\end{array}$ & 58565 & 228857 & 12293 & 205359 \\
\hline B & restored & indirect & $\begin{array}{c}\text { Block } \\
\text { composite }\end{array}$ & $\begin{array}{l}\text { Resin } \\
\text { cement }\end{array}$ & 58565 & 228857 & 12293 & 205359 \\
\hline C & restored & indirect & $\begin{array}{l}\text { Lithium } \\
\text { Disilicate }\end{array}$ & $\begin{array}{c}\text { Resin } \\
\text { cement }\end{array}$ & 58565 & 228857 & 12293 & 205359 \\
\hline
\end{tabular}

Table 2 - Analyzed FEM models

To simulate polymerization shrinkage effects of adhesive layers and bulk fill composite, the thermal expansion approach was used. Shell elements were employed for modelling of the adhesive layers (fig. 1e). The assumed values of linear thermal expansion coefficient and shell thickness are reported in Table 1. In addition, by assuming a one-degree drop in temperature, the adhesive layer and bulk fill composite volume would shrink and generate stress at the tooth-restoration interface. The occlusal static load was set equal to $600 \mathrm{~N}[17,18]$. The load was vertically applied and uniformly distributed on the surface (Fig. 1f) in combination with the shrinkage effect. Finally, fixed zero nodal displacements on the bottom cutting surfaces were assigned. As the analysis was performed considering a non-failure condition, all the materials were assumed to behave as elastic materials throughout the entire deformation. 


\section{Results}

The first maximum principal stress was adopted to assess the effects due to the applied investigation conditions. Three different analyses of class II MOD adhesive restorations were carried out under polymerization shrinkage and under occlusal load simulation and shrinkage together and one analysis on the sound tooth under loading only. External and internal behavior of the materials involved in the different direct and indirect inlay restorations were analyzed by observing displacements and shrinkage stress values, on the left and on the right of the pictures respectively placed.

Figure 2a shows the mechanical behavior of the full sound tooth. In this image the stress pattern and distribution under loading was quite simple but totally or partially different from all restored models: $\mathrm{A}, \mathrm{B}$ and $\mathrm{C}$.

In the sound tooth, the occlusal load was homogeneously distributed (Fig. 2a) from the top enamel side down through the dentine (Fig. $2 b$ and $2 c$ ). The compressive and tensile maximum loading stresses displayed by blue areas reduced progressively with a displacement effects of the cusps (Fig. 2b and 2c, left side).

The stress absorbing effects of dentine ( $\mathrm{E}=18 \mathrm{GPa}$ ) were confirmed in the cut sections (Fig. $2 \mathrm{~b}$ and $2 \mathrm{c}$, right side), where the enamel $(80 \mathrm{GPa})$ totally transferred the loading to the more elastic dentine layer behind which allowed the cusps to stretch elastically.

Figures 3a-c, left side, show from an occlusal and lateral viewpoint the displacements maps of the full model A, B and C under the resin based materials shrinkage effect only. Fig 3a, in particular, demonstrates the high displacement stress, on the left, of the bulk fill composite and, on the right, the critical shrinkage stress all around the margins. Fig. 3b, on the contrary, shows the limited marginal stresses in terms of displacement, on the left, and of shrinkage, on the right, of model B.

Fig. 3c show a similar displacement (on the left) and shrinkage map distribution (on the right) to fig. $3 \mathrm{~b}$ for model $\mathrm{C}$, where lithium disilicate was considered with shrinkage of a $70 \mu \mathrm{m}$ thick resin cement sub-layer.

Fig 4 and fig 5 show two cut of the models A, B and C under polymerization shrinkage. Here there are reproduced mesial (fig. 4a-4b-4c) and central section's (fig. 5a-5b-5c) of, respectively, resin composite bulk material (model A), resin composite block inlay (model B) and lithium disilicate inlay (model C). Internal displacement and principal shrinkage stresses under shrinkage are illustrated. It appears evident that substantial differences (MPa) exist where bulk composite polymerization shrinkage extends to the base of dentinal tissue (fig. 3a, 4a and 5a). A very low resin cement shrinkage restricted to the $70 \mu \mathrm{m}$ thick layer did not affect the dentine (fig. $3 \mathrm{~b}, 4 \mathrm{~b} 5 \mathrm{~b}$, right side) as compared to the model A behavior.

Displacements of model B and C (Fig. 3b and 3c, left side) were similar to each other but significantly different from model A. Under the combined effects of the polymerization shrinkage and of the occlusal loading the highest displacement map and the highest principal stress distribution were recorded in model A (fig 6a), in the mesial box (fig. 7a) and in the central cavity (fig. 8a). They produced a severe cusp deflection deeply extended to the all of restored tooth (fig. 6a) as compared to the shrinkage stress (Fig. 3a), located all around the enamel-restoration and dentine-restoration interfaces at the top side as well as at the lateral walls of the cavity boxes. Stresses were present 
mesially and distally (figures $6 \mathrm{a}, 7 \mathrm{a}, 8 \mathrm{a}$ on the right side) at the top side as well as at the lateral walls of the cavity boxes.

In models $\mathrm{B}$ and $\mathrm{C}$, on the contrary, an important total stress relief was externally present at the occlusal location (fig.6b and 6c, left side) and at the mesio-central locations (fig. 7b, 7c and 8b, 8c, left side). No significant difference in terms of stress and strain was observed between B and C models. The different values of the Young's modulus, assumed for restored materials, differently affect the displacements. In the model $\mathrm{A}$, the maximum displacement values in the $\mathrm{Z}$ direction were localized on the top surface of restored filling material, whereas displacements tends to uniformly distribute on the occlusal surface of the restored tooth in the model B and C (Fig. $6 \mathrm{~b}$ and $6 \mathrm{c}$ ), where a restoring material was used.

Looking to the figures $2 \mathrm{a}, 2 \mathrm{~b}$ and $2 \mathrm{c}$ it is clear how the model $\mathrm{B}$ and $\mathrm{C}$ mechanical behavior is close to the sound one in terms of displacement stress $(\mathrm{mm})$. Only on the occlusal surface as well as on the sound tooth (fig 2) there exist restricted stress concentration areas because of application loading. The principal shrinkage-stress relief pattern between model B and $\mathrm{C}$ was mechanically analogous but not identical, with a different displacement map for the proximal box.

Consideration of materials and tissues with a wide range of Young's modulus differently influenced the observed behavior. Fig $3 a, 3 b$ and $3 c$ showed results of the internal stressing conditions of the three models at different locations. In Fig 3a and 3c, model A always showed the highest stress concentrations internally at the cavity floor but reducing from the bottom to the top in the center of the cavity where the internal dentinal floor was less deep (Fig 3c). In the same slice, for models B and C, different situations were investigated and the curves of stress-strain were less than in Model A. Shrinkage stress concentration were limited at the $70 \mu \mathrm{m}$ cement layer of the dentinal deep floor boxes (mesial and distal) interface of Models B and C. But the pattern of internal stress pattern (Fig. 3b) appeared close to the sound tooth. The food chewing stress effect was positively absorbed by the restorative inlay materials despite the different Young's modulus (20 GPa versus $70 \mathrm{GPa}$ ).

\section{Discussion.}

It was already demonstrated that direct posterior resin nano-composite [1], machinable block composite and ceramic materials can successfully be used to restore decayed teeth [2]. These materials are able to resist occlusal loading of adhesive class I and II restorations. Direct or indirect restorative materials and technologies are in use extensively but there is no consensus on what is the best choice for the general dentist [3].

In class II MOD restorations, marginal debonding and fracture may occur depending on several factors, including: cavity-margin-angles, cavity shape and size, C-factor, isthmus distance and adhesive material chemical and physical properties $[4,6-8,11,14,18]$.

Stresses generated during mastication $[5,17,18,21]$ and those related to the polymerization shrinkage $[5,9,10,18,20,21-24]$ are also considered main causes of adhesive dental restorations damage or failure. 
The effects of different cavity-margin-angles and of food stiffness applied occlusally, have been simulated to study the final adhesive class II mechanical behavior by means of 3D FE analysis [18].

Computer aided design (CAD) and manufacturing (CAD), 3D solid modelling and Finite Element Analyses (FEA) are fully employed technologies in dentistry today as essential tools in non destructive investigations [25-27]. Finite element analysis, in particular, has been also carried out to predict damage or marginal adhesive restorations failure and results have established different internal stress propagation in direct Class II MOD versus indirect resin composite restorations [5].

Dejak and Mlotkowski [5] confirmed that stresses in direct Class II resin composites arise principally from polymerization shrinkage. Our findings are in general agreement with this but their choice of material property values were dissimilar to ours. In that case [5], the authors investigated a low modulus composite direct filling material $(\mathrm{E}=5.6 \mathrm{GPa})$ and a comparable low modulus resin cement under the inlay $(E=5.2)$. In both cases $0.7 \%$ linear shrinkage was assumed.

Resin material thickness and its Young's modulus strongly influence stress redistribution at adhesive interfaces particularly stress relief into the cusps [6,9]. A recent study [18], suggested that in Class II MOD inlay, a $95^{\circ}$ cavity-margin-angles under a $600 \mathrm{~N}$ load gives a more relevant picture of principal stress relief. The present investigation has confirmed these data $[5,7,9,18]$ but focused on cavity design, simulated loading and Young's Modulus of the materials involved.

A resin block inlay composite with a Modulus of $20 \mathrm{GPa}$, as investigated in model $\mathrm{B}$, and shown in fig. $6 \mathrm{~b}, 7 \mathrm{~b}, 8 \mathrm{~b}$ performed well in terms of displacement and principal marginal and internal stresses. This material in combination with a $70 \mu \mathrm{m}$ layer of $\mathrm{E}=6 \mathrm{GPa}$ significantly reduced the fracture risk than in the direct Class II adhesive resin composite restoration of model A (Fig. 3a, 3b, 3c). The final mechanical behavior of model B (Fig. 6b, $7 \mathrm{~b}$ and $8 \mathrm{~b}$,left side) was really close to that of the sound tooth model (fig. 2a, 2b and 2c, left side). Lithium disilicate with a Modulus of $70 \mathrm{GPa}$ as investigated in model $\mathrm{C}$ and shown in fig. $6 \mathrm{c}, 7 \mathrm{c}$ and $8 \mathrm{c}$, left side, showed minimal differences in the stresses within the proximal box. A bulk fill resin composite $(\mathrm{E}=12 \mathrm{GPa}$, model $\mathrm{A})$ with only $1 \%$ linear shrinkage gave the highest stresses (Fig 6a, 7a and 8a) under loading and shrinkage.

When compared to the other model restorations, model A showed marginal and internal principal stress concentrations mainly located at the deep floor-walls angles, mesial and distal sides, than in the middle of the restoration (Fig 6a, 7a, 8a). This is in according with previous investigations and independently from studies of rounded angles of the cavity-floor walls $[5,7]$ and probably to put in relation to the total bulk composite high shrinkage in the deep cavity.

With models B and C (fig. 6b, 6c, 7b, 7c, 8b, 8c), shrinkage and loading together did not affect the mechanical behavior negatively. Stress relaxation in both model B and C depended upon the modulus of the inlay restoration. In all these images, however, there is an absence of the bridging effect of sound dentine (Fig. 2a, 2b, 2c) able to homogeneously redistribute the maximum stress of $600 \mathrm{~N}$ under the loaded enamel, with the wall-to-wall stretching mechanical behavior previously described [20]. Models B and C (fig. 6a, 6b and 7b, 7c, and 8b, 8c) showed a more favorable performance than model A with elastic biomechanics similar to the sound tooth model (fig. 2b, 2c). These findings are in agreement with experimental and clinical evidence $[2,3,29,30]$. 


\section{Conclusions:}

With the limit of the present linear analysis and of the postulated conditions of isotropic material behavior, it is possible to conclude:

1. Bulk filling resin composite with $1 \%$ polymerization shrinkage negatively affected the marginal and internal stress adaptation in large class II MOD adhesive restorations;

2. Machinable resin block composite and lithium disilicate adhesive inlay restorations adequately performed under loading and shrinkage. Both inlay systems limited displacements and absorbed stress comparably to a sound tooth.

\section{References}

1. Sideridou ID, Karabela MM, Vouvoudi ECh. Physical properties of current dental nanohybrid and nano fill light-cured resin composites. Dent Mater. 2011; 27:598-607.

2. Li RW, Chow TW, Matinlinna JP. Ceramic dental biomaterials and CAD/CAM technology: state of the art. J Prosthodont Res. 2014; 42:208-16.

3. Mendonça JS, Neto RG, Santiago SL, Lauris JR, Navarro MF, de Carvalho RM. Direct resin composite restorations versus indirect composite inlays: one-year results J Contemp Dent Pract. 2010; 11:25-32.

4. Liu $\mathrm{X}$, Fok A, Li H. Influence of restorative material and proximal cavity design on the fracture resistance of MOD inlay restoration. Dent Mater. 2014; 30:327-33.

5. Dejak B, Mlotkowski A. A comparison of stresses in molar teeth restored with inlays and direct restorations, including polymerization shrinkage of composite resin and tooth loading during mastication. Dent Mater. 2015; 31:77-87.

6. Ausiello P, Apicella A, Davidson CL. Effect of adhesive layer properties on stress distribution in composite restorations--a 3D finite element analysis. Dent Mater. 2002; 18:295-303.

7. Ausiello P, Rengo S, Davidson CL, Watts DC. 2004. Stress distributions in adhesively cemented ceramic and resin-composite Class II inlay restorations: a 3D-FEA study. Dent Mater. 2004; 20:862- 872

8. Boaro LC, Brandt WC, Meira JB, Rodrigues FP, Palin WM, Braga RR. Experimental and FE displacement and polymerization stress of bonded restorations as a function of the C-Factor, volume and substrate stiffness. J Dent. 2014; 42:140-148.

9. Versluis A, Tantbirojn B, Pintado MR, DeLong R, Douglas WH. 2004. Residual shrinkage stress distributions in molars after composite restoration. Dent Mater. 2014; 20: 554-564

10. Al Sunbul H, Silikas N, Watts DC .Polymerization shrinkage kinetics and shrinkage-stress in dental resin-composites. Dent Mater. 2016; 32:998-1006

11. Inukai T, Abe T, Ito Y, Pilecki P, Wilson RF, Watson TF, Foxton RM. Adhesion of indirect MOD resin composite inlays luted with self-adhesive and self-etching resin cements. Oper Dent. 2012; 37:474-84. 
12. L.C. Boaro, F. Gonçalves, T.C. Guimarães, J.L. Ferracane, C.S. Pfeifer, R.R. Braga. Sorption, solubility, shrinkage and mechanical properties of low-shrinkage commercial resin composites. Dent Mater 2013; 29: 398-404

13. Leprince JG, Palin WM, Vanacker J, Sabbagh J, Devaux J, Leloup G. Physico-mechanical characteristics of commercially available bulk-fill composites J Dent 2014; 42:993-1000.

14. Van Dijken JW, Pallesen U. A randomized controlled three year evaluation of "bulk-filled" posterior resin restorations based on stress decreasing resin technology. Dent Mater._2014; 30:245-251

15. Zorzin J, Maier E, Harre S, Fey T, Belli R, Lohbauer U, Petschelt A, Taschner M. Bulk-fill resin composites: polymerization properties and extended light curing. Dent Mater. 2015; 31:293-301.

16. Khvostenko D, Salehi S, Naleway SE, Hilton TJ, Ferracane JL, Mitchell JC, Kruzic JJ. Cyclic mechanical loading promotes bacterial penetration along composite restoration marginal gaps. Dent Mater. 2015; 31:702-10

17. Ausiello P, Franciosa P, Martorelli M, Watts DC. Numerical fatigue 3D-FE modeling of indirect composite-restored posterior teeth. Dent. Mater 2011; 27:423-

18. Ausiello P, Ciaramella S, Garcia-Godoy F, Gloria A,Lanzotti A, Maietta S, Martorelli M. The effect of cavity-margin-angles and bolus stiffness on the mechanical behavior of indirect resin composite class II restorations. Dent Mater 2016; 24:109-5641

19. Braga RR, Koplin C, Yamamoto T, Tyler K, Ferracane JL, Swain MV. Composite polymerization stress as a function of specimen configuration assessed by crack analysis and finite element analysis. Dent Mater. 2013; 29:1026-33

20. Ausiello P, Apicella A, Davidson CL, Rengo S. 3D-finite element analyses of cusp movements in a human upper premolar, restored with adhesive resin-based composites. $\mathrm{J}$ Biomech 2001; 34:1269-77.

21. Rues S, Huber G, Rammelsberg P, Stober T. Effect of impact velocity and specimen stiffness on contact forces in a weight-controlled chewing simulator. Dent Mater. 2011; 27:12671272.

22. Davidson CL, Feilzer AJ. Polymerization shrinkage and polymerization shrinkage stress in polymer-based restoratives. J Dent 1997; 25:435-44

23. Soares CJ1, Bicalho AA, Tantbirojn D, Versluis A. Polymerization shrinkage stresses in a premolar restored with different composite resins and different incremental techniques. $\mathrm{J}$ Adhes Dent 2013;15:341-350

24. Ferracane JL, Hilton TJ. Polymerization stress - Is it clinically meaningful? Dent Mater. 2016; 32:1-10.

25. Giordano M, Ausiello P, Martorelli M Accuracy evaluation of surgical guides in implant dentistry by non-contact reverse engineering techniques.Dent Mater. 2012; 28:178-185.

26. Martorelli M, Ausiello P, Morrone R. A new method to assess the accuracy of a Cone Beam Computed Tomography scanner by using a non-contact reverse engineering technique.J Dent. 2014; 42:460-465. 
27. Martorelli M, Ausiello P. A novel approach for a complete 3D tooth reconstruction using only 3D crown data. International Journal on Interactive Design and Manufacturing. 2013; 7:125-133

28. Rodrigues FP, Silikas N, Watts DC, Ballester RY. Finite element analysis of bonded model Class I 'restorations' after shrinkage. Dent Mater. 2012; 28:123-32.

29. Melo Freire CA, Borges GA, Caldas D, Santos RS, Ignácio SA, Mazur RF. Marginal Adaptation and Quality of Interfaces in Lithium Disilicate Crowns - Influence of Manufacturing and Cementation Techniques. Oper Dent. 2016 Nov 1. [Epub ahead of print]

30. Belli R, Petschelt A, Hofner B, Hajtó J, Scherrer SS, Lohbauer U. Fracture Rates and Lifetime Estimations of CAD/CAM All-ceramic Restorations. J Dent Res. 2016; 95:67-73.

\section{Figures}

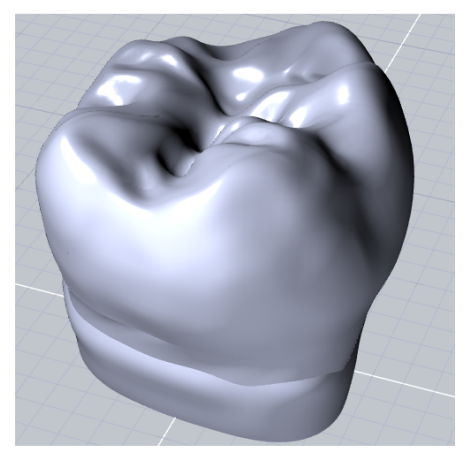

a)

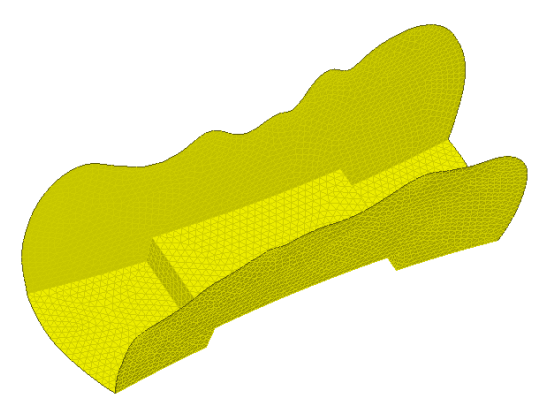

d)

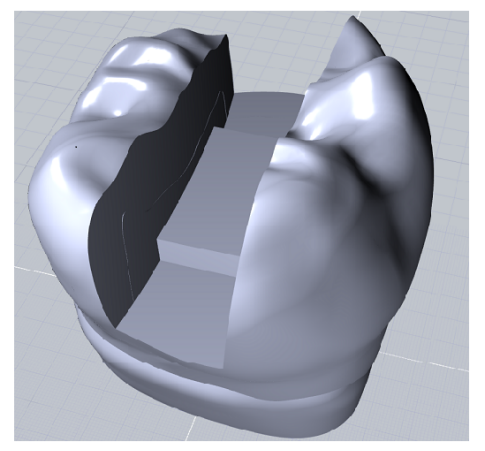

b)

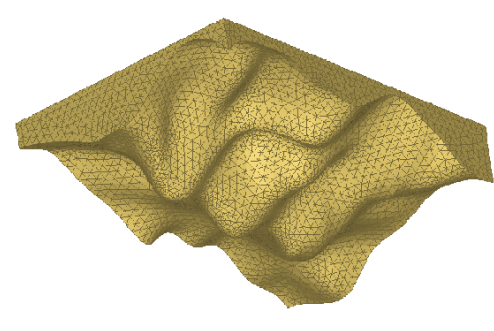

e)

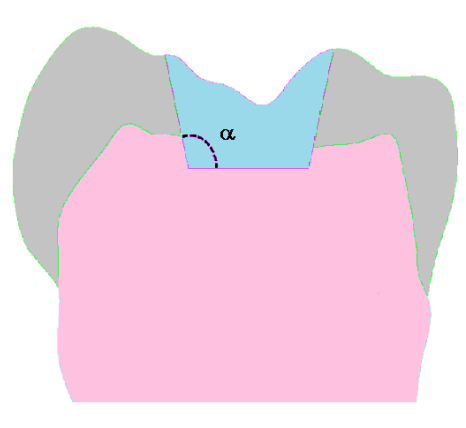

c)

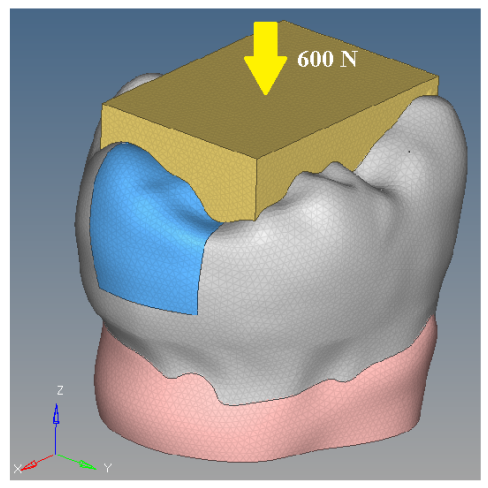

f)

Fig. 1 - 3D model of restored tooth. a) Geometric model; b) Cavity; c) Margin angle of the cavity restoration; d) Resin and luting cement model; e) Bolus on the occlusal surfaces; f) Overall FEM model 

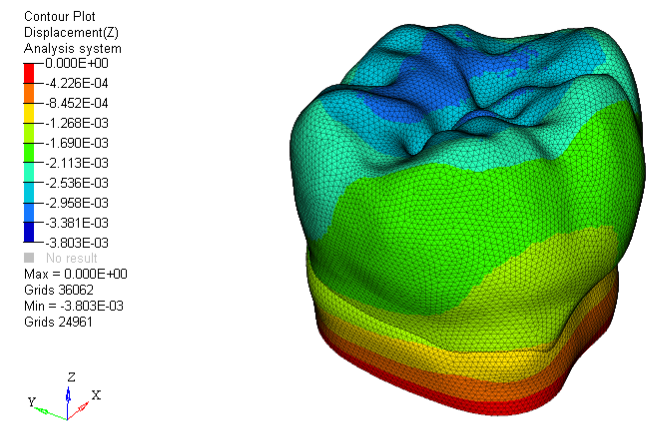

sound.h3d
Subcase 2 (Load)

Contour
Elemen
Analysi
Simple
Vimle
Val Value Fitter Range - 15.00000
17.000 $\mathbf{Z}_{-9.3625++10}^{-3.340}$ $-9.923 E+100$

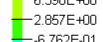

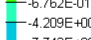
$-\begin{aligned}-7.742 E+00 \\ -1.128 E+01\end{aligned}$ Max $=1.699 \mathrm{E}+01$
Grids 25072

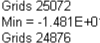
$y^{2} t^{x}$

a)
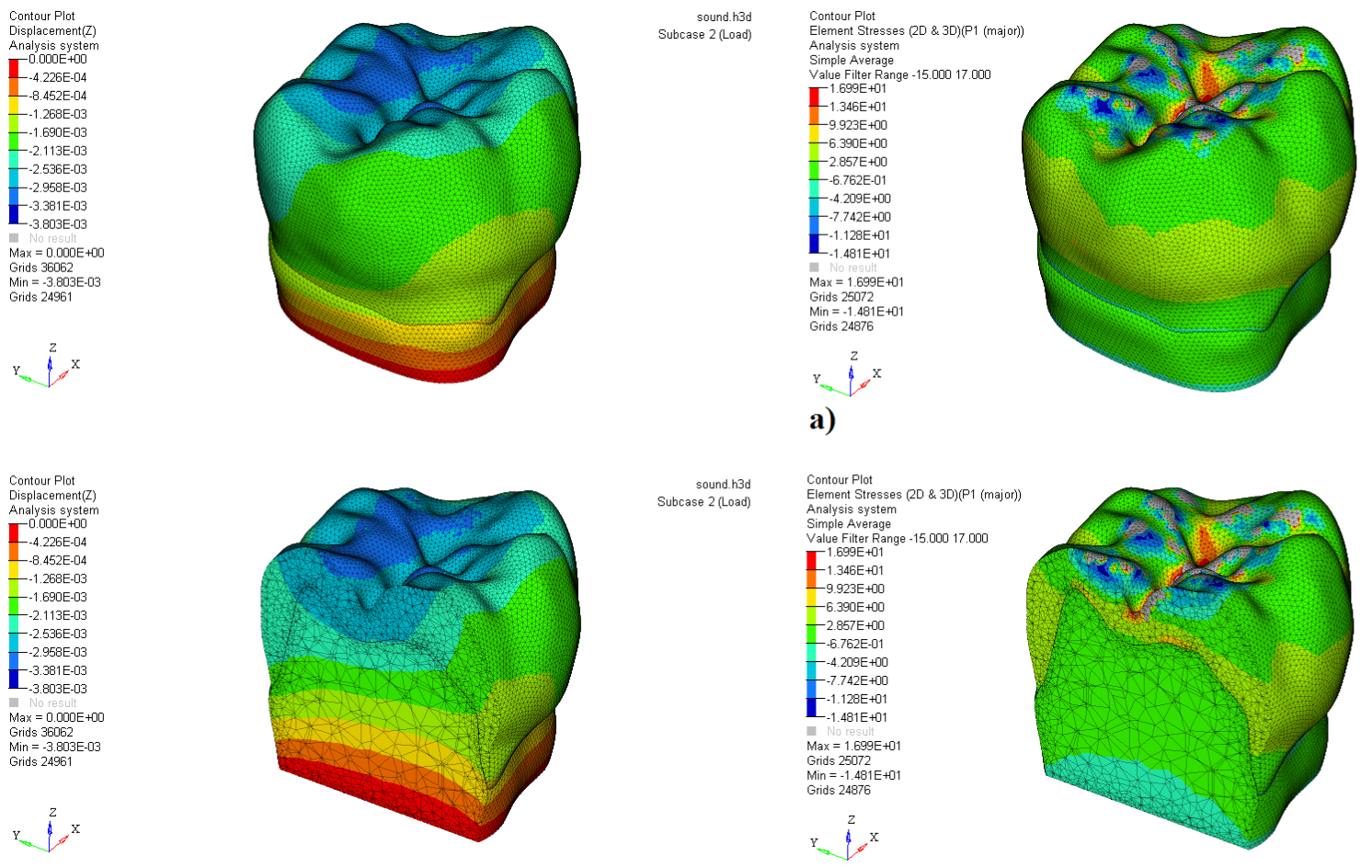

sound.h3d
Subcase 2 (Load)

b)
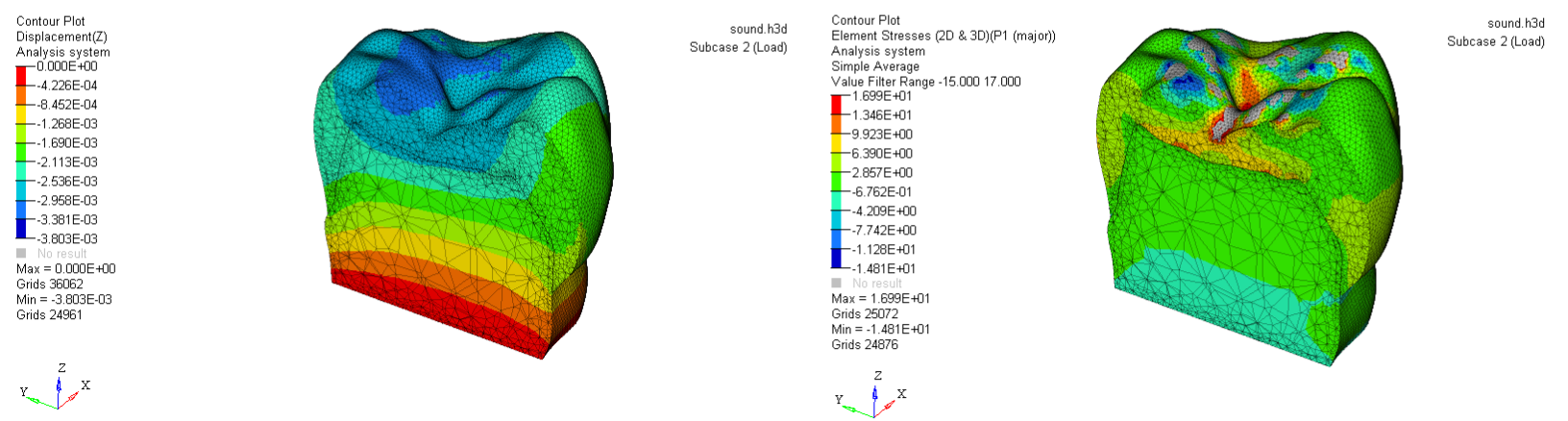

c)
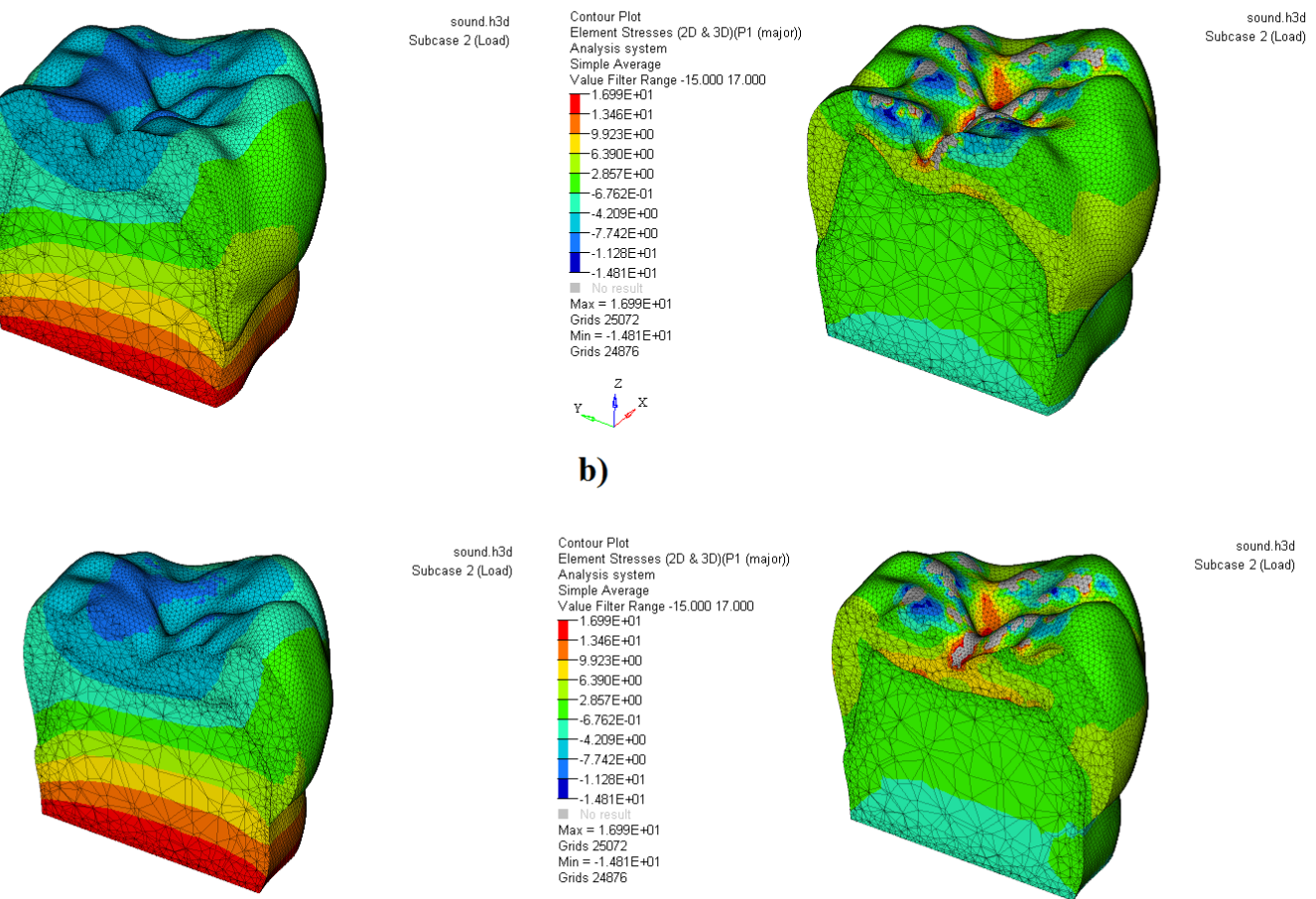

Fig. 2 - Displacements $(\mathrm{mm})$ under loading of the model sound tooth 

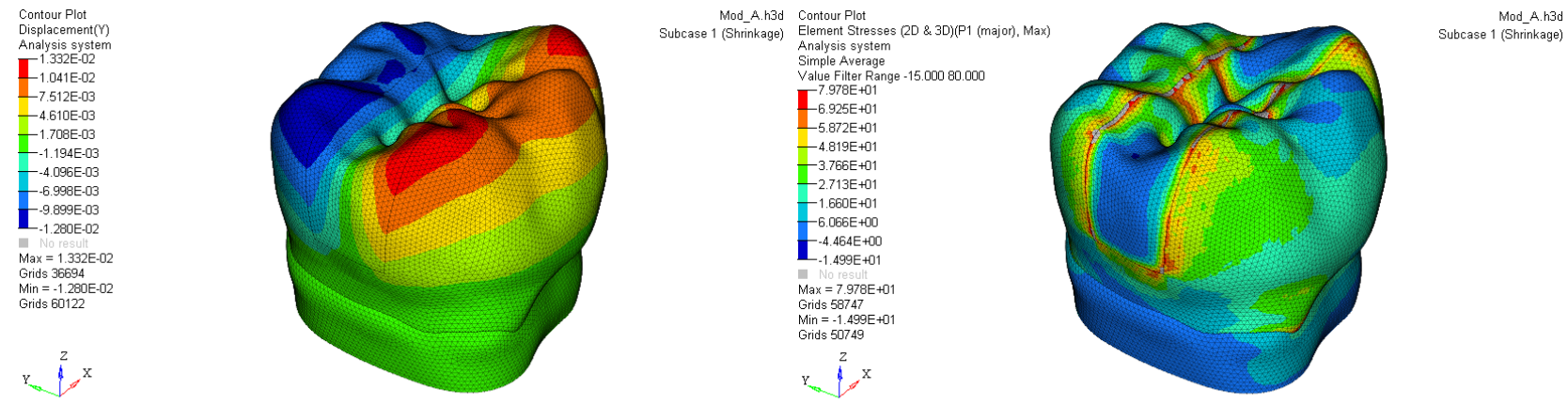

a)
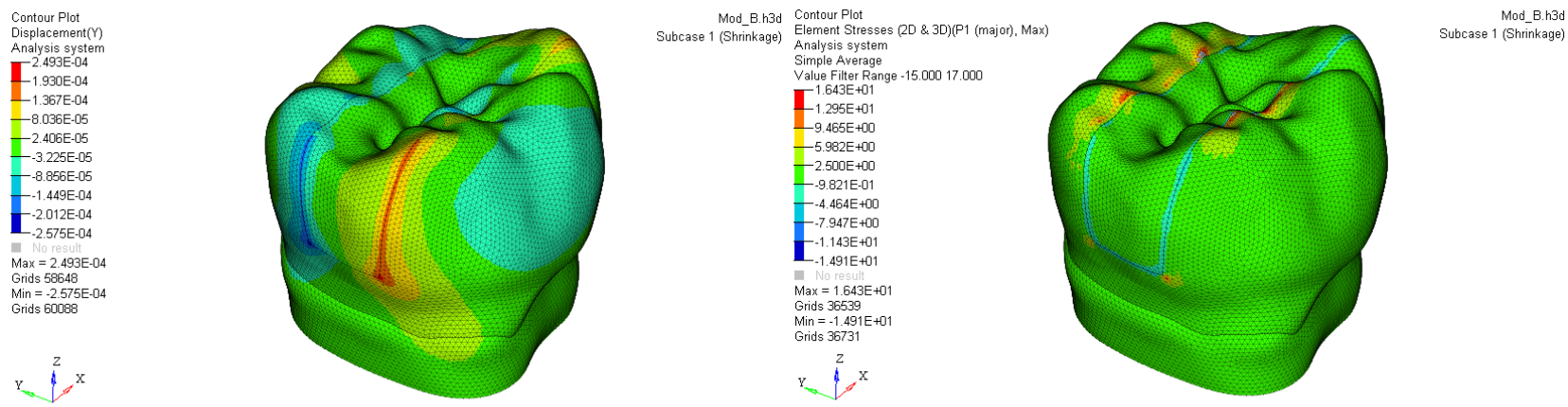

b)
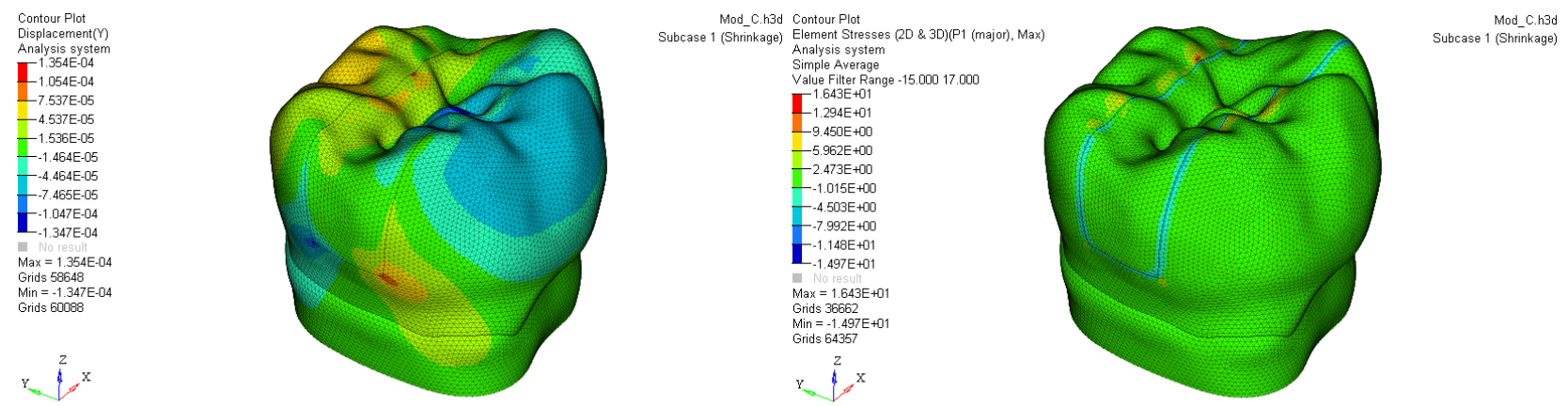

c)

Fig. 3 - Displacements $(\mathrm{mm})$ and first principal stress distribution (MPa) under shrinkage effect, on the cut section along the bucco-lingual direction, corresponding to mesial floor boxes. a) Model A; b) Model B; c) Model C. 

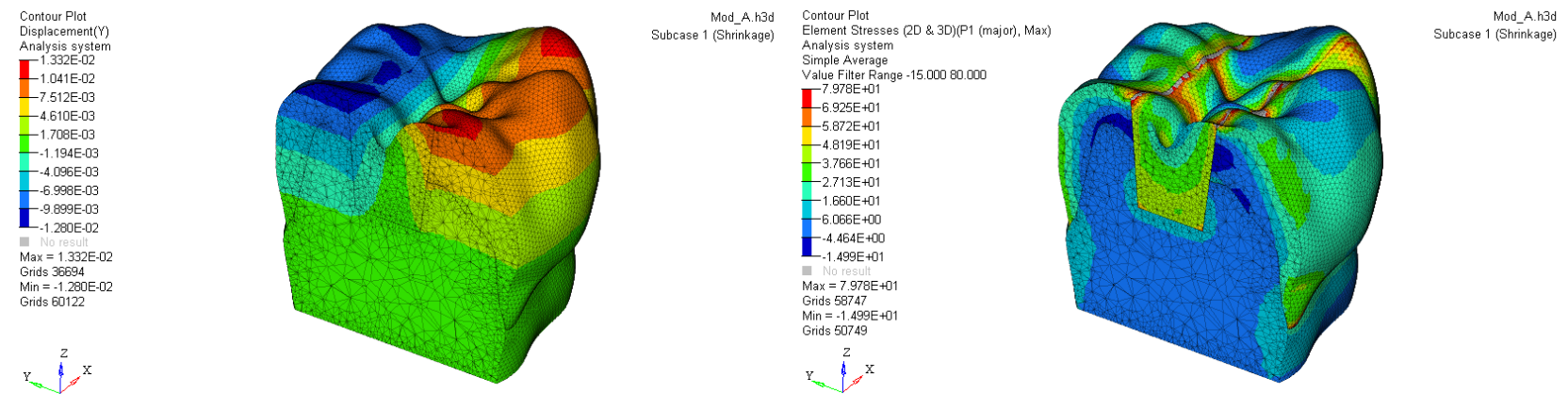

a)
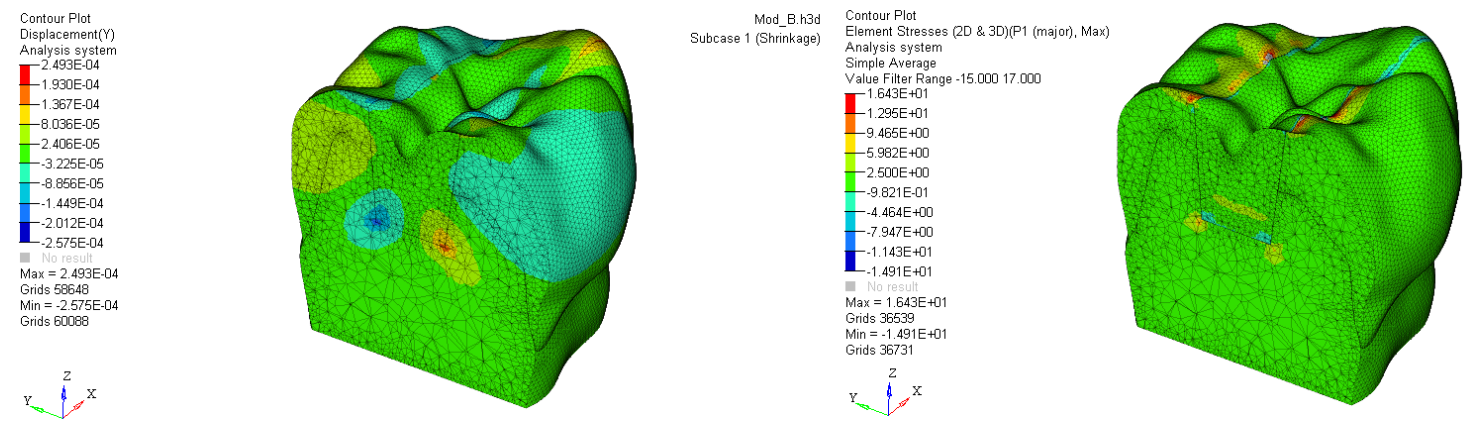

Mod_E.h3d
Subcase 1 (Shrinkage)

b)
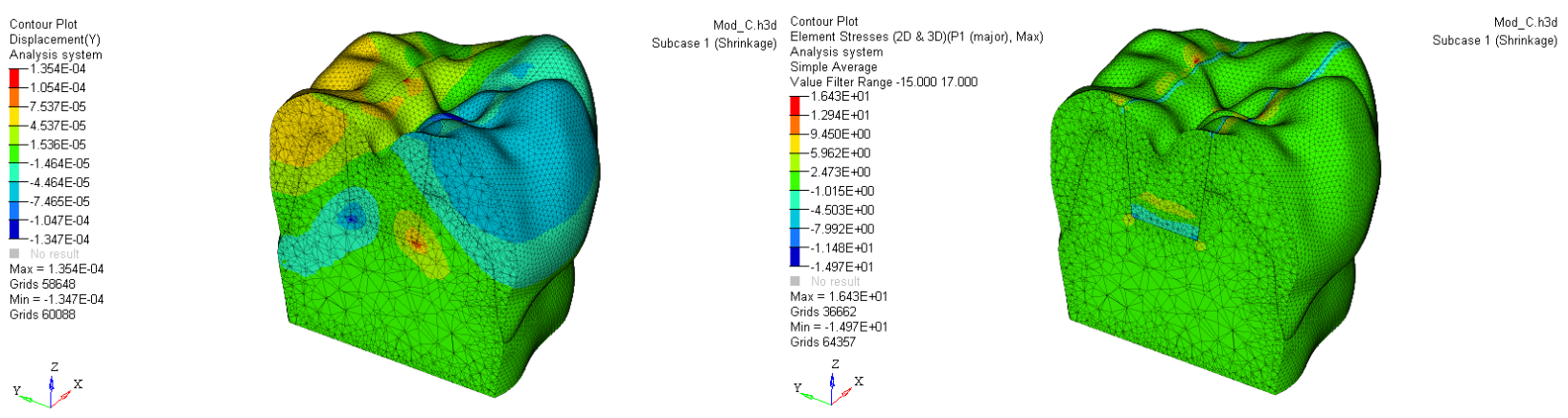

c)

Fig. 4 -. Displacements ( $\mathrm{mm}$ ) and first principal stress distribution (MPa) under shrinkage effect, on the cut section along the bucco-lingual direction, corresponding to mesial floor boxes. a) Model A; b) Model B; c) Model C. 

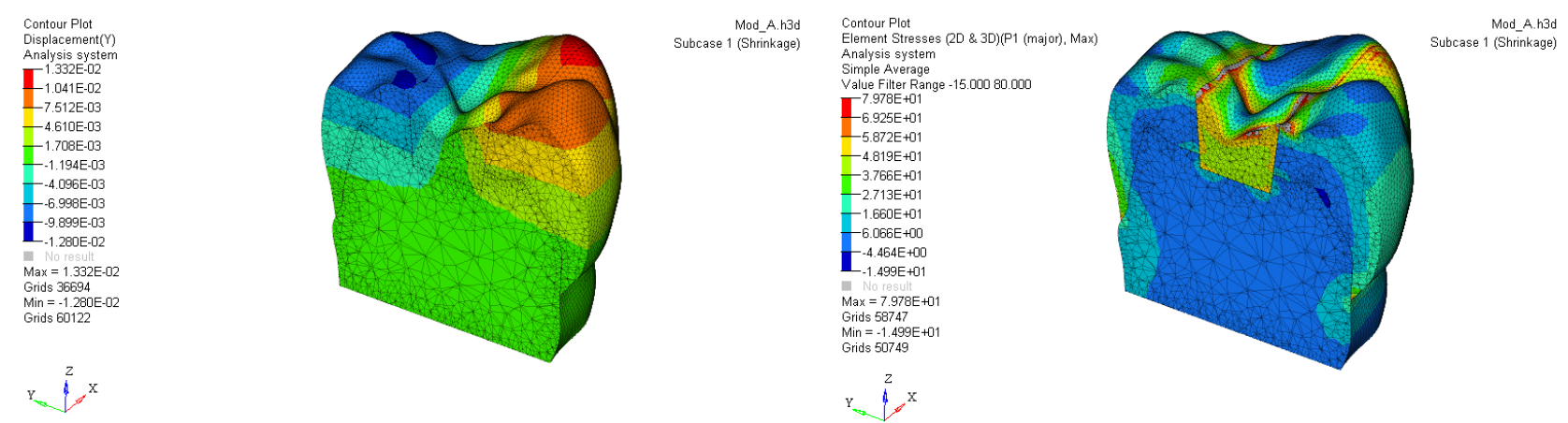

a)
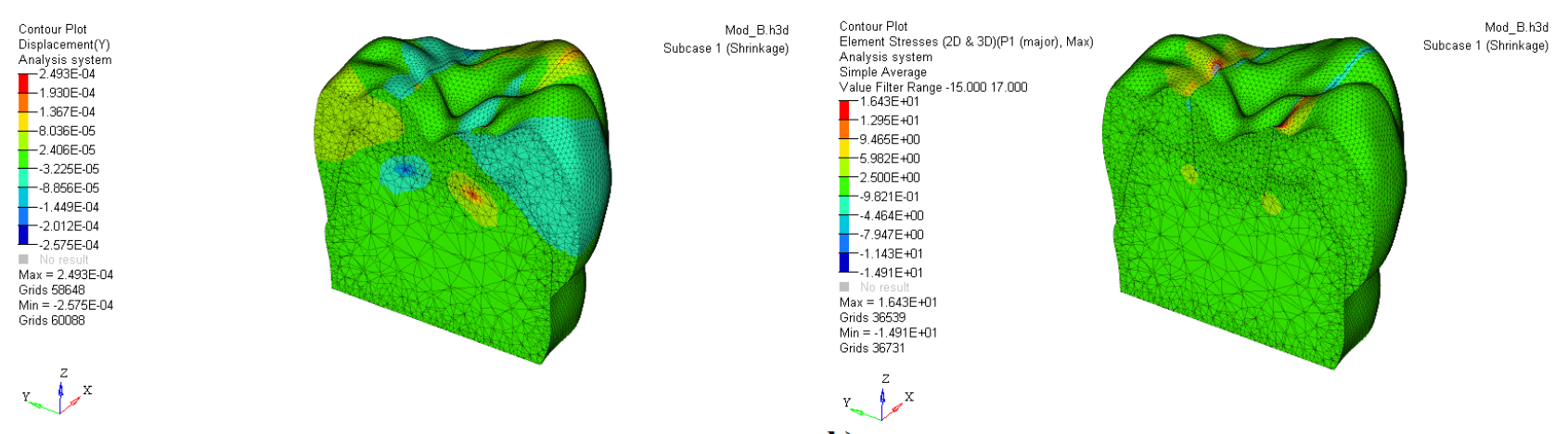

$x^{2}+x$

b)
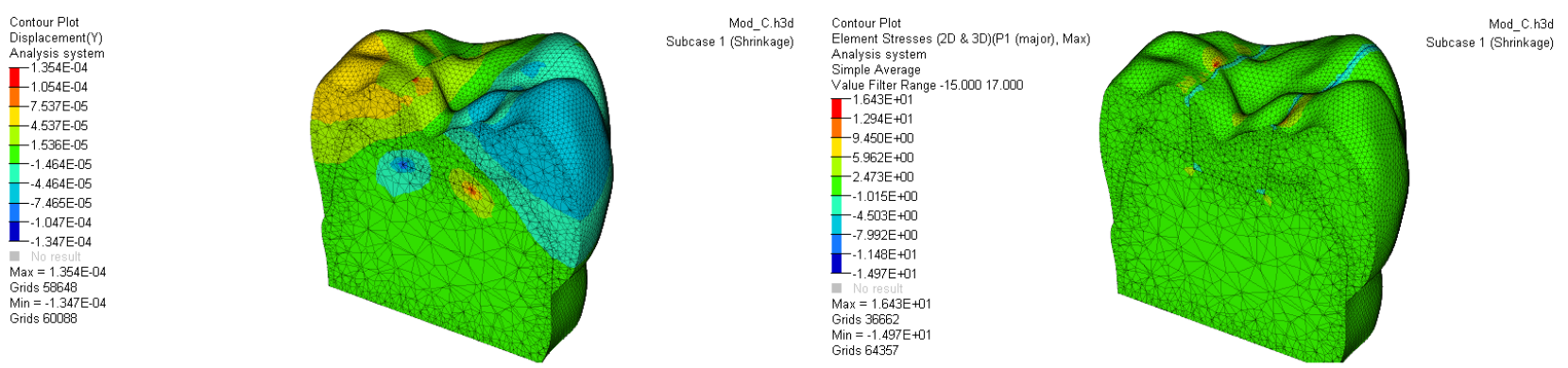

c)

Fig. 5 - Displacements $(\mathrm{mm})$ and first principal stress distribution (MPa) under shrinkage effect, on the cut section along the bucco-lingual direction, at the center of the tooth. a) Model A; b) Model B; c) Model C 

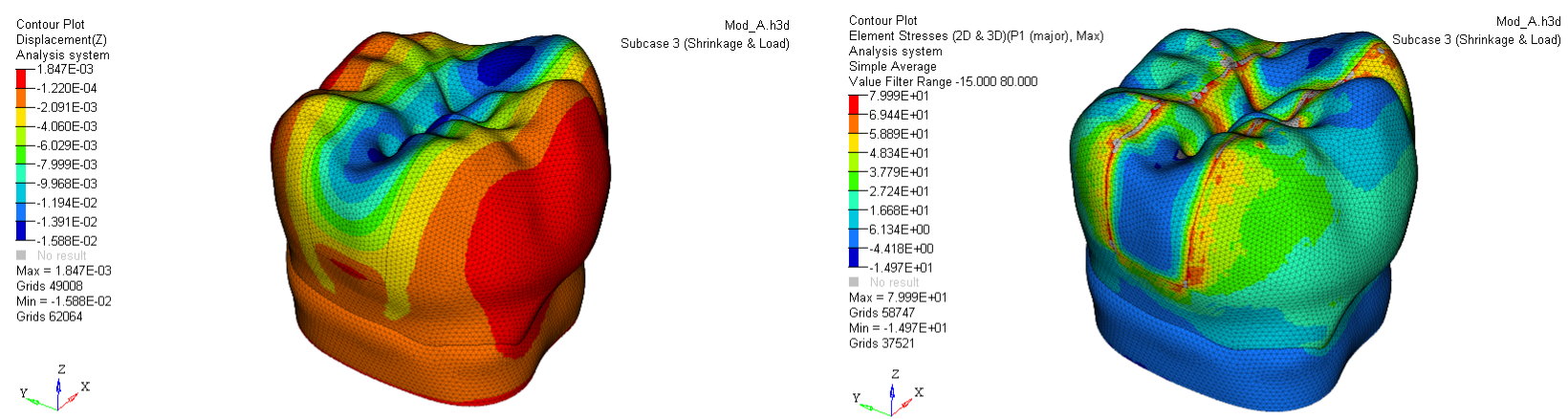

a)
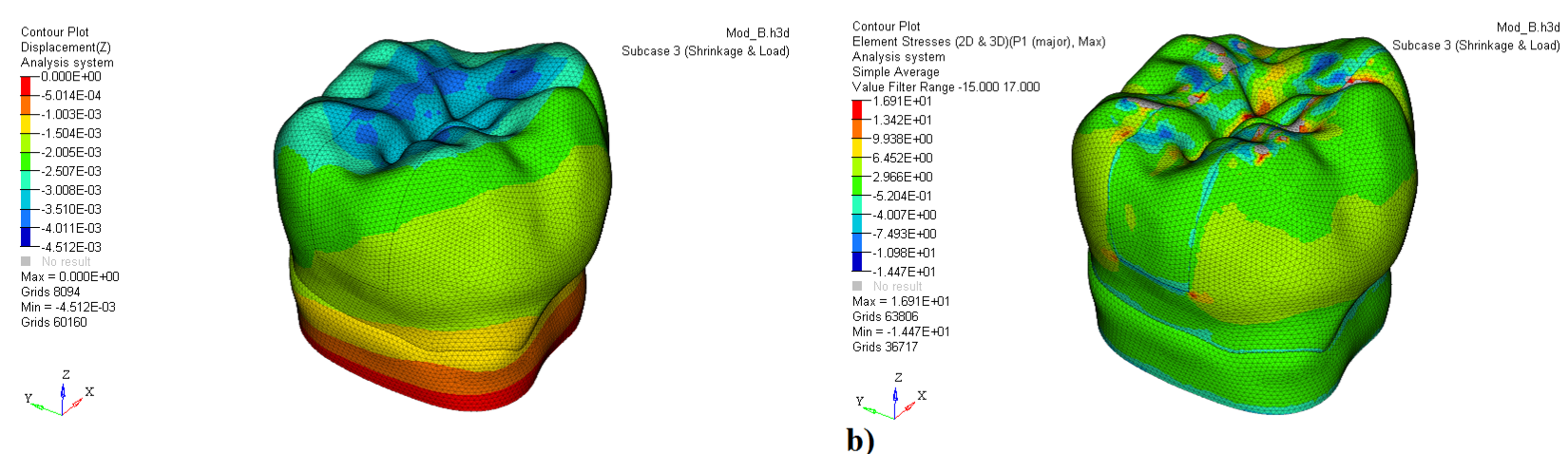

b)
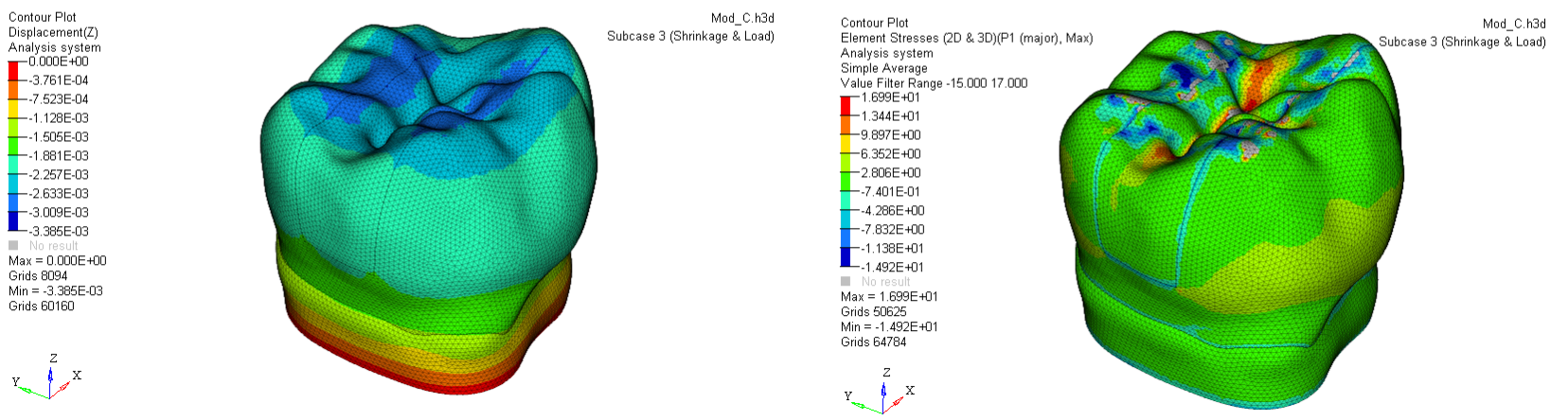

c)

Fig. 6 - Displacements $(\mathrm{mm}$ ) and first principal stress distribution (MPa) under shrinkage and occlusal load. a) Model S; b) Model A; c) Model B; d) Model C. 

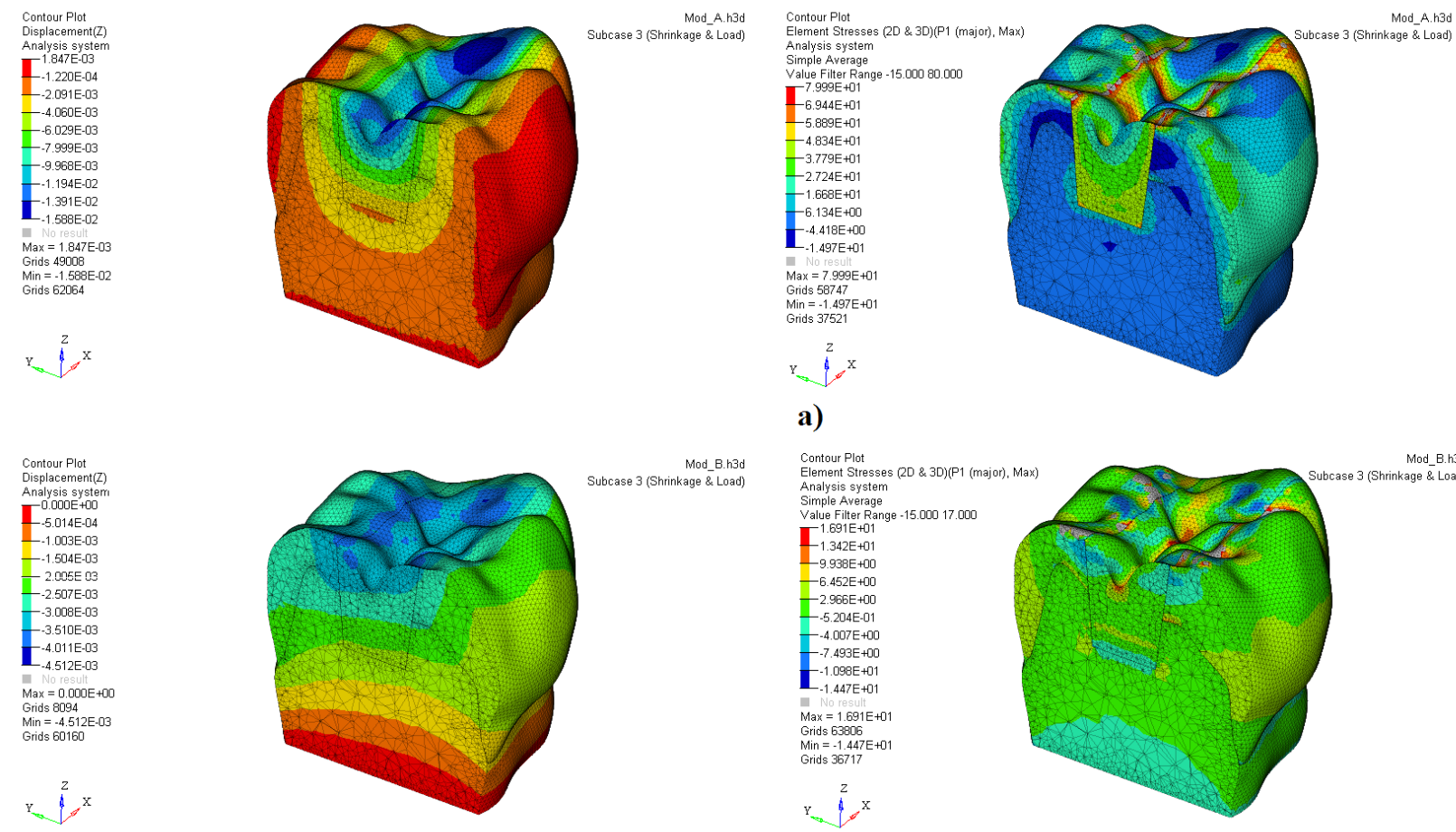

a)

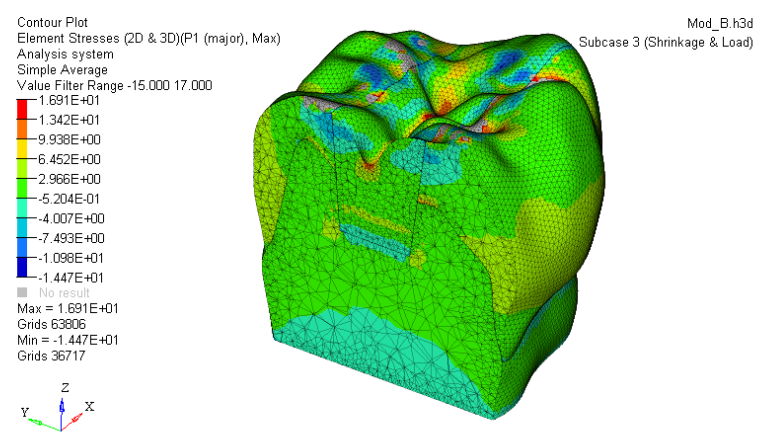

b)

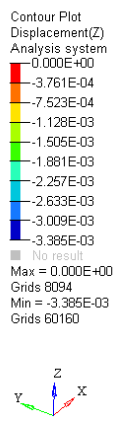

Mod_C. h3d
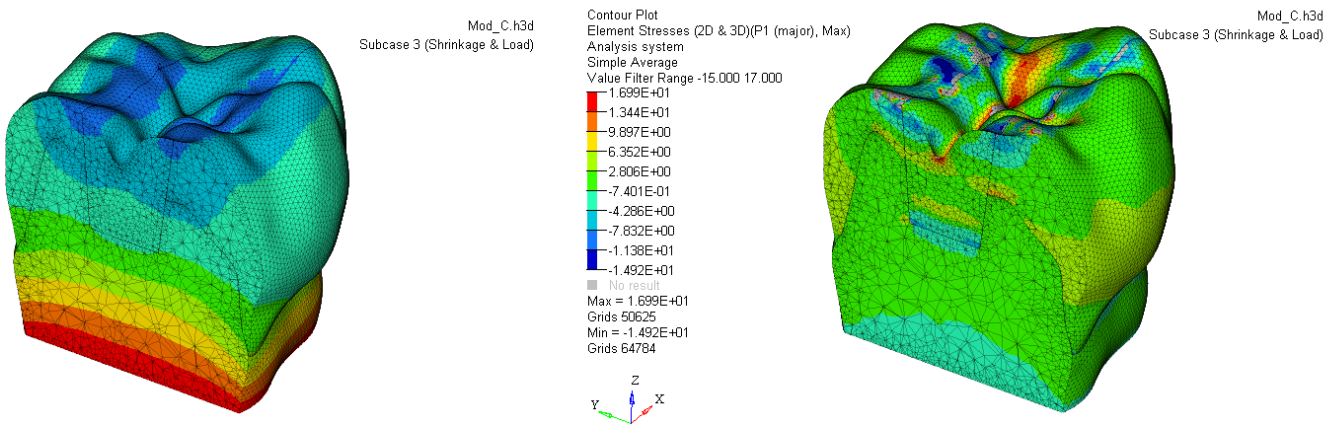

c)

Fig. 7 - Displacements $(\mathrm{mm})$ and first principal stress distribution $(\mathrm{MPa})$ under shrinkage and occlusal load, on the cut section along the bucco-lingual direction, corresponding to mesial floor boxes. a) Model $\mathbf{S}$; $b$ ) Model A; c) Model B; d) Model C. 

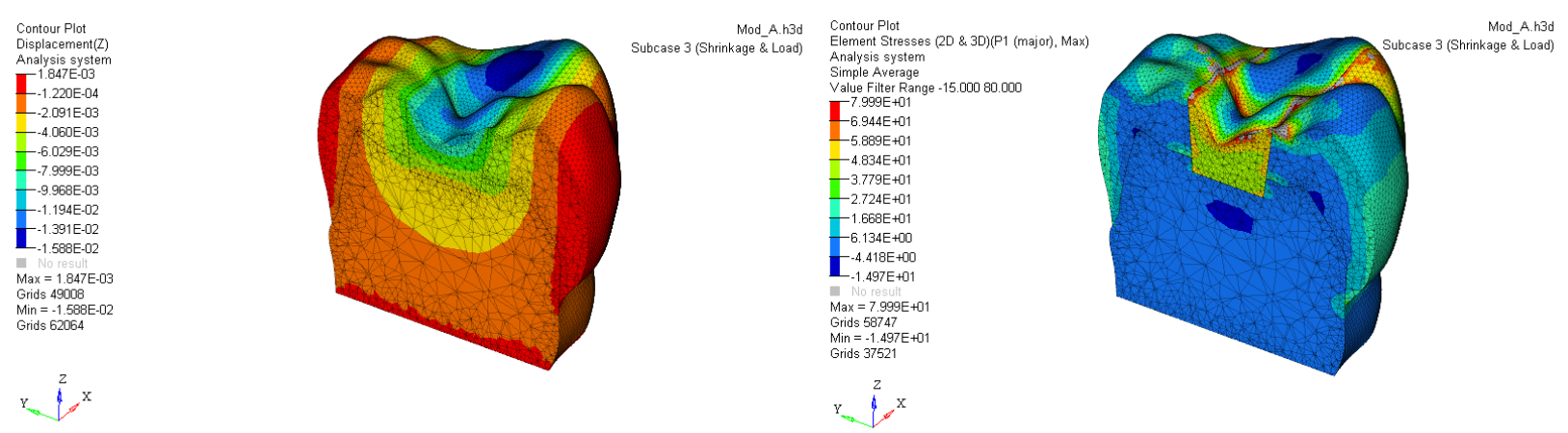

a)
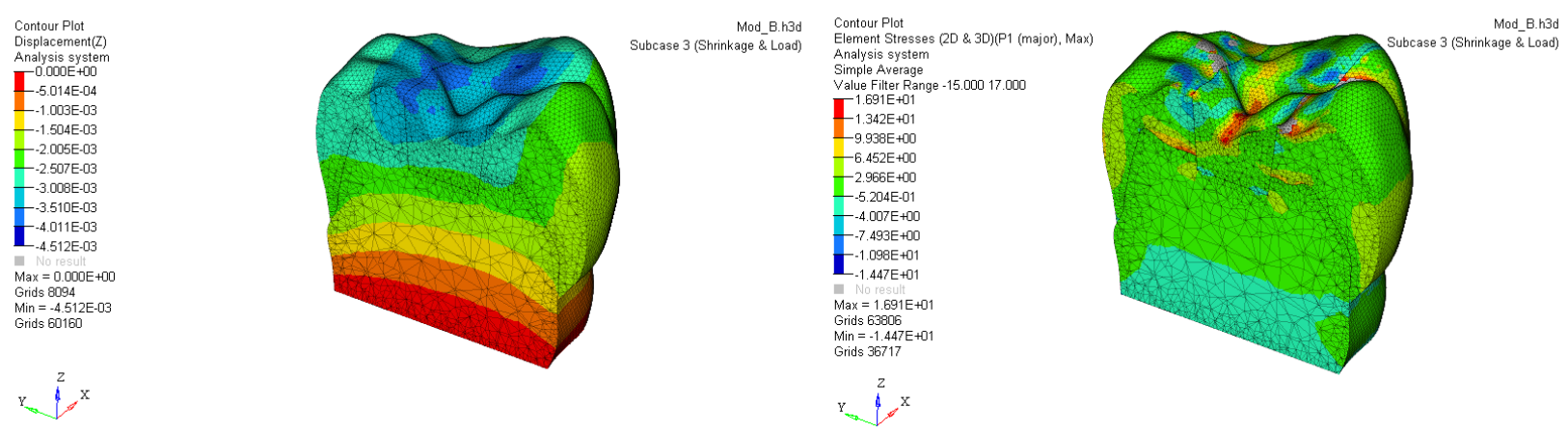

b)
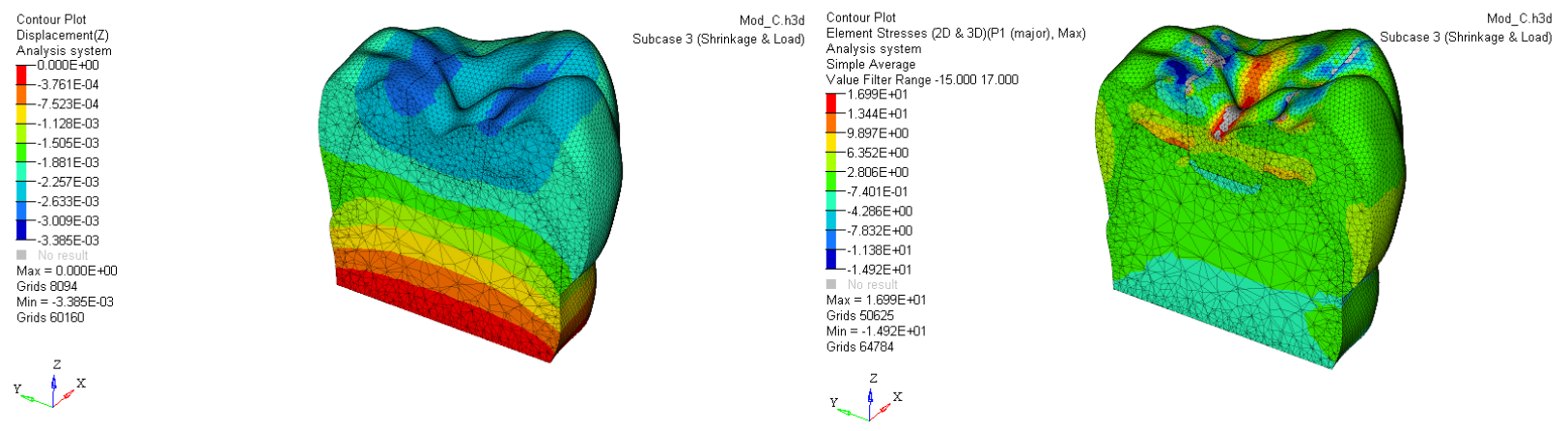

c)

Fig. 8 - Displacements $(\mathrm{mm})$ and first principal stress distribution $(\mathrm{MPa})$ under shrinkage and occlusal load, on the cut section along the bucco-lingual direction, at the center of the tooth. a) Model S; b) Model A; c) Model B; d) Model C. 